\title{
A comparison of hip adduction to abduction strength ratios, in the dominant and non-dominant limb, of elite academy football players
}

\author{
Victoria C. Griffin ${ }^{1}$, Tony Everett ${ }^{2}$, I an G. Horsley ${ }^{1}$ \\ 1. Physiotherapy Dept, English Institute of Sport, Manchester, UK. 2. School of Healthcare Studies, Cardiff University, \\ Cardiff, Wales, UK.
}

Correspondence: Ian G. Horsley, PhD. Address: English Institute of Sport, Gate 13 Sportcity, Etihad Campus, Rowsley Street, Manchester, M11 3FF, UK. Email: Ian.Horsley@eis2win.co.uk

Received: August 27, 2015

DOI : $10.5430 /$ jbei.v2n1p109

Online Published: October 28, 2015

Accepted: October 7, 2015

URL: http://dx.doi.org/10.5430/jbei.v2n1p109

\section{Abstract}

Context: Hip adduction and abduction strength plays an important role in the treatment and prevention of groin injuries in football players. Currently there are no reliable baseline values for uninjured football player's hip adduction: abduction muscle strength ratios.

Objective: To examine whether normal hip adduction: abduction strength ratios can be established in uninjured football players. To compare this data, and establish if there is an asymmetry between the dominant and non-dominant limb.

Methods: Twenty, English Premier League academy football players $18.45( \pm 2.06)$ years, $72.6( \pm 5.56) \mathrm{kg}, 180.15$ $( \pm 7.97) \mathrm{cm}, 3$ left limb dominant, and 17 right limb dominant were included in the study. Eccentric and concentric hip adduction and abduction strength of the dominant and non-dominant leg was tested using a Cybex isokinetic dynamometer.

Results: The concentric ratio on the dominant limb was $1.59( \pm 0.19)$ and on the non-dominant limb $1.45( \pm 0.31)$. The eccentric ratio on the dominant limb was $1.45( \pm 0.32)$ and on the non-dominant limb $1.26( \pm 0.26)$. Overall the ratios were higher on the dominant limb and this was statistically significant $P \leq .05$. Abduction strength was similar bilaterally. Adduction strength was $18 \%-22 \%$ greater on the dominant limb.

Conclusions: The greater ratios on the dominant limb are due to increased adductor strength as a result of the kicking action. Elite football player's hip adduction: abduction strength ratios should be 1.45-1.6 on the dominant limb and 1.25-1.45 on the non-dominant limb. The adductors on the dominant limb should be $18 \%-22 \%$ stronger than the non-dominant limb. Ratios outside these parameters could indicate the player is at risk of injury. Further research is required to support muscle imbalance as a cause of injury and identify injury risk thresholds for groin injuries in football players.

\section{Key words}

Hip, Adductor, Abductor, Strength, Soccer, Groin, Impingement 


\section{Introduction}

Adductor muscle injury is among the most common injuries in football ${ }^{[1,2]}$. The incidence has been reported to be 1.0 and 1.1 per 1,000 playing hours ${ }^{[3,4]}$. A recent systematic review of prospective studies by Walden et al., $2015^{[5]}$ concluded that groin injuries account for between 7\%-13\% of all injuries, with males having twice the incidence of females

Prospective studies have shown an adductor strain incidence of $10 \%-18 \%$ of all injuries in football players ${ }^{[6]}$. This means that a male professional soccer team will suffer an average of seven groin injuries per season, with greater than $50 \%$ of them being unavailable for selection for at least one week ${ }^{[4]}$.

Groin pain is a symptom that can symptomatic of several musculoskeletal dysfunctions including hernia, pubic bone oedema/avulsion fractures, adductor strains, adductor tendinopathies, external abdominal oblique tear, nerve entrapment, rectus abdominus tear, as well as hip joint pathology ${ }^{[4,7,8]}$.

Previous studies have identified that in addition to having a previous groin injury ${ }^{[1,9]}$, strength deficits and flexibility are predisposing factors to adductor strains in various athletic populations ${ }^{[10-17]}$. There is support for an association between lower adductor to abductor strength ratios and adductor strains in ice hockey players ${ }^{[16,18]}$. A study comparing ice hockey player's pre-season strength revealed that players who did not get an adductor injury had a $95 \%+$ adductor to abductor strength ratio bilaterally ${ }^{[16]}$. Players who went on to sustain an adductor strain had an average pre-injury $78 \%$ adductor to abductor strength ratio on that leg. This study suggests its results are not sport specific and would be transferable to other sports in which athletes commonly sustain hip adductor strains. They recommend maintaining an $85 \%+$ strength ratio to prevent adductor strains. However this study was conducted using hand held dynamometry which has not been deemed a reliable measurement tool for isotonic hip adduction: abduction ${ }^{[19]}$. A recent systematic review of randomized controlled trials of groin prevention programmes ${ }^{[20]}$ concluded that no evidence of significant reduction in the number of groin injuries after completing a groin injury prevention programme.

The purpose of this study was to examine whether normal hip adduction: abduction strength ratios can be established in uninjured football players. Aim is to compare this data and establish if there is an asymmetry between the dominant and non-dominant limb.

\section{Methods}

\subsection{Study design}

Following ethical approval from Cardiff University School of Healthcare Studies 20 participants were recruited from full time academy and reserve team squads at an English Premier League football club. An effect size for the primary outcome measure of 0.7 was used to have a power of $80 \%{ }^{[21]}$. Preliminary power analysis based on an alpha level of 0.05 resulted in a minimal sample size of 17 subjects according to Gpower version 3 . Accommodation of $15 \%$ was made for drop outs and therefore 20 subjects were recruited. A Pilot study was carried out on two subjects, two weeks prior to the first day of data collection to allow for any methodology/protocol to be altered if necessary.

\subsection{Participants}

Participants were deemed appropriate for the study if they met the following Inclusion criteria:

1) Ages 16-23

2) Male Gender has been associated with differences in lower limb kinematics; therefore the study included male participants only ${ }^{[22]}$

3) Full time elite footballer players

4) Able to identify dominant kicking limb 


\section{5) Participating in full pre-season training programme}

Participants were excluded from participation in the study if they reported one or more of the following exclusion criteria: History of pathology in the hip or groin region over last 2 seasons, history of hip or groin surgery. These players will have received rehabilitation and altered their muscle imbalances based on this to prevent injuries and therefore do not reflect the general footballing population ${ }^{[19]}$, ambidextrous kicker-any adaptations based on kicking action will be bilateral and comparison will not be possible, not participating in full preseason training for any reason, under 16 or over 23 years of age, any limitations or neurological involvement which would influence performance of the strength assessment, lumbar spine pathology over the last 2 seasons and subjects must be pain-free on strength testing.

Prior to commencing the study all participants signed an informed consent form approved by the Cardiff University School of Healthcare Studies Ethics Committee and the Premiership football club. All procedures were within the ethical standards of Cardiff University School of Healthcare Studies Ethics Committee.

\subsection{Procedures}

Testing took place over an 8 days period at the end of pre-season training so players were deemed at peak condition. This meant participants were unlikely to be excluded due to injury as they had not played competitive matches but they had been working on cardiovascular and strength work to prepare for the start of the season. In addition this was also a good time to take the measurements and have baseline data for the season in case of future injury.

Data collection took place in the isokinetic room at the club training ground. The venue was therefore familiar to all participants. All subjects were familiar with using the isokinetic machine to assess knee flexion and extension strength, but this was the first time any of them had used an isokinetic machine to test hip strength. To eradicate the well documented learning effect, subjects were tested initially and then tested again one week later using identical protocols ${ }^{[21]}$. Data from the first day was not included for analysis ${ }^{[23]}$. Subjects were randomised as to whether they tested dominant (kicking limb) or non-dominant limb (standing limb) first. Subjects voluntarily disclosed their dominant limb when signing the consent form.

Subject positioning has been challenging especially with studies in standing shown to risk excessive lumbar spine involvement and thus lack validity ${ }^{[24-27]}$. The use of a fixation belt and back rest designed to prevent pelvic and lumbar movement during assessment has been identified as a method to ensure valid results ${ }^{[21,26]}$. This set up was therefore replicated by the present study with the subject in side lying, accounting for limb weight and gravity, against a back board with a belt to ensure lumbopelvic stability (see Figure 1).

Figure 1. Depicting Cybex Norm set-up with backboard positioned (A) to prevent lumbopelvic motion and thus ensure standardised subject positioning

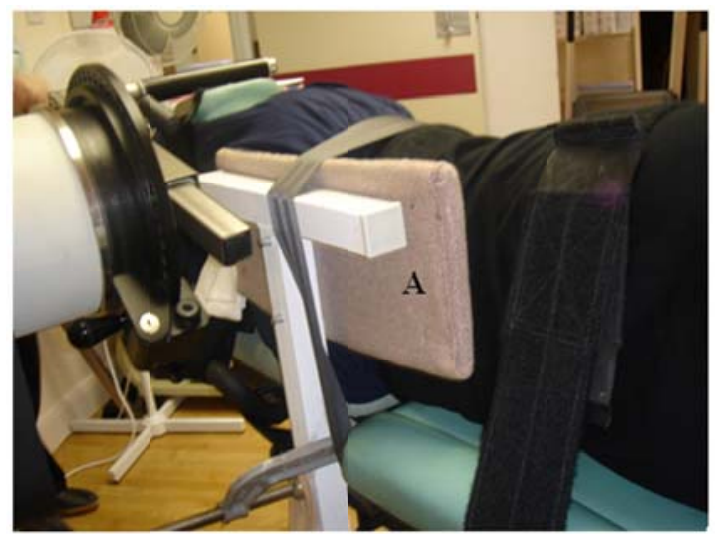

This set up has been shown to demonstrate high intra-rater reliability $(\mathrm{ICC}=0.99)$, but lacks adequate inter-rater reliability $(\mathrm{ICC}=0.8)$. Therefore it was determined to make one researcher in the present study responsible for undertaking all measurements to ensure necessary reliability. 
Participants were requested to wear club training kit, T-shirt and shorts for testing without footwear. This clothing ensured abduction range of motion would not be restricted by clothing and all participants were uniform.

Experimental set-up is depicted in Figure 2.

Figure 2. Depicting Equipment Set-Up. A: Shows seatbelt used to securely position subjects. B: Depicts Cybex Norm dynamometer with axis positioned in line with the axis of the hip joint at mid distance between pubic symphysis and greater trochanter. C: Padding for providing patient comfort when undertaking resistance contractions. D: Velcro to securely fasten limb onto Cybex Norm lever arm (tension especially important for adduction tests). E: Cybex Norm computer and software set-up for data recording.

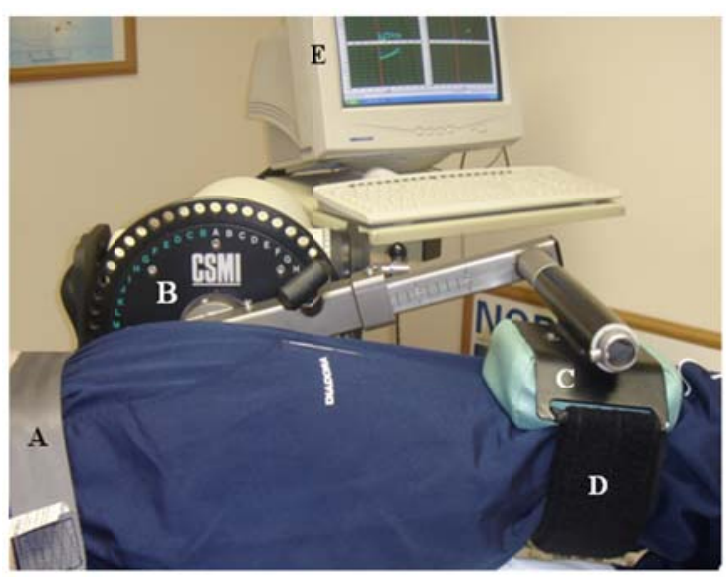

A belt was securely fastened at the level of the anterior superior iliac spine, with the buckle positioned behind the back rest to ensure subject comfort. In order to undertake hip strength measurements the dynamometer of the Cybex Norm has to be positioned at the axis of motion of the hip joint. To determine this accurately and ensure standardisation throughout testing the head of the femur was assumed to be positioned at the halfway point of the line joining the greater trochanter and the symphysis pubis ${ }^{[26]}$. The height of the dynamometer, the length of the hip knee adapter, and the chair positioning were adjusted accordingly to ensure that the rotation of the head of the femur was at the same level as the dynamometer pivot and therefore standardization was ensured.

A total of 4 straps were attached to the subject: ankle, thigh, abdomen, and chest. The hip and knee adapter was applied at the level of the quadriceps tendon, immediately superior to the patella on the testing side. Once subject comfort was ensured the full range of motion of each limb for each subject was determined to set target testing area. Subjects were instructed to move the limb through as far a range of hip abduction as comfortable. These dimensions were maintained for each side and each setup for all sessions.

\subsection{Data recording}

1) Information sheet issued, consent attained

2) Participant arrives at isokinetic room at allocated time

3) Participants weighed on digital recording scales, electronic height recorded

4) Participants requested to undertake 10 minute warm up on the static bike at level 4 resistance ${ }^{\text {[21] }}$

5) Two minutes timed rest

6) Instructions provided that full effort must be given on all testing repetitions, but that practice repetitions need not be maximal effort

7) Subjects given emergency stop button for Cybex Norm and instructions to press this to end testing at any time

8) Participants positioned and strapped into isokinetic machine as outlined above. Each subject limbs assessed in a previously determined randomly allocated order. The tester blinded to limb dominance

9) Cybex Norm HUMAC programme begins with computer guided instructions for ROM, practice reps/rests

10) Testing undertaken for: 
a) Concentric Abduction: Concentric Adduction

b) Eccentric Abduction

c) Eccentric Adduction

Testing was undertaken at 30 degrees per second and then repeated at 60 degrees per second, with 5 repetitions undertaken for each of a-c. Identical order of testing was undertaken for each participant to ensure standardisation of any fatigue effect. These speeds ensure validity as discussed in the literature review ${ }^{[21]}$.

No encouragement or feedback was provided to participants during the testing procedure as this has been reported to influence outcome ${ }^{[28]}$.

11) Programme completed and participant released from the isokinetic machine

12) After a 2-min-rest period participant positioned on the isokinetic machine to commence testing on the other side

13) Protocol repeated using Cybex Norm HUMAC programme

14) Participant released from isokinetic machine

15) Testing steps 1-13 repeated one week later

\subsection{Statistical analysis}

Raw data output was exported and saved as a Microsoft excel file. A specially written excel macro was then run on the data to determine the maximum torque, in Newton meters, produced by each subject for each of the 8 different contractions undertaken during testing. Data normalisation accounting for subject height and weight was performed, and the results used to calculate ratios of adductor to abductor strength for eccentric and concentric contractions at each of the two different speeds. This resulted in eight data sets for subsequent analysis. Ratios were calculated by dividing the adductor peak torque by the abductor peak torque in all cases as previously described ${ }^{[18]}$.

A $95 \%$ confidence interval was used with a $P$-value of 0.5 throughout analysis. SPSS version 16 was used to undertake all statistical analysis.

\section{Results}

Data examining participant demographics are presented first, followed by analysis of the effect of limb dominance on hip adductor to abductor strength ratios involving contraction types, undertaken at different speeds. To determine whether parametric statistics could be used to analyse the data, the normality of each variable was tested using a KolmogorovSmirnov Test. If variables were normally distributed paired $t$-tests were used to determine the significance of pair wise comparison of dominant non-dominant limb group. Data not normally distributed were analysed using Wilcoxon Rank Test to determine the significance of pair wise comparison between dominant and non-dominant limb group.

A $95 \%$ confidence interval was used with a $P$-value of 0.5 throughout analysis. SPSS version 16 was used to undertake all statistical analysis. Study participant demographics are presented in Table 1 as mean $\pm \mathrm{SD}$ (range).

Table 1. Subject demographics

\begin{tabular}{ll}
\hline & $\mathbf{N}=\mathbf{2 0}$ \\
\hline Age (years) & $18.45 \pm 2.06$ \\
Weight (kg) & $72.6 \pm 5.56$ \\
Height (cm) & $180.15 \pm 7.97$ \\
Left Limb Dominant & 3 \\
Right Limb Dominant & 17 \\
\hline
\end{tabular}


Figure 3. Eccentric abductor strength at 30

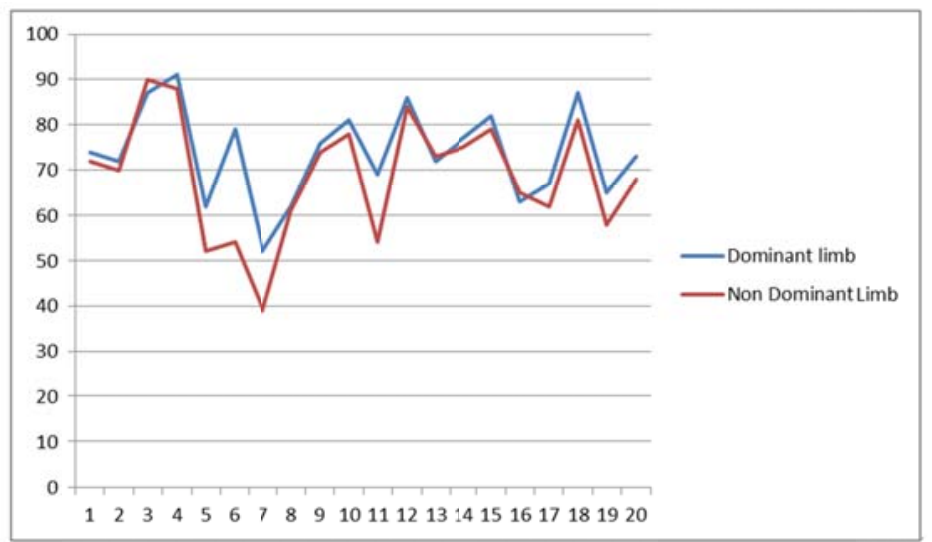
degrees per second

Figure 4. Eccentric adductor strength at 30

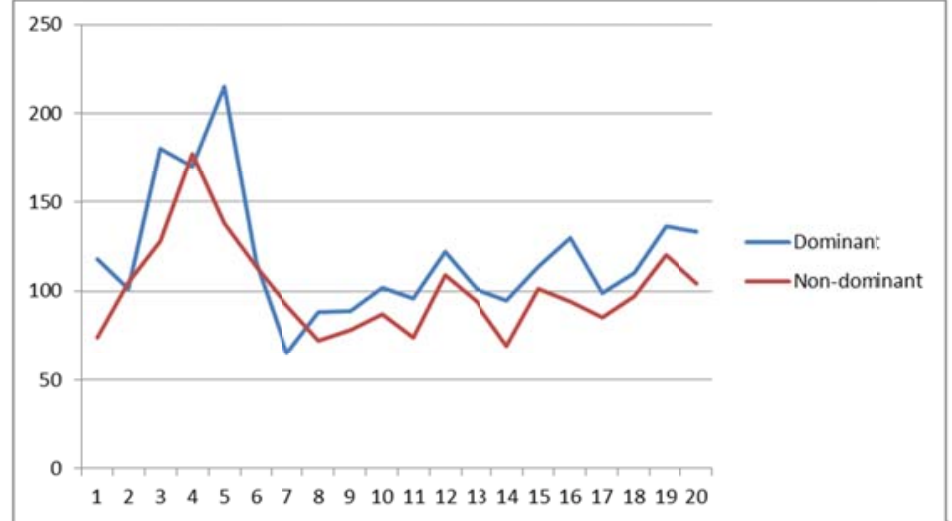
degrees per second

Figure 5. Concentric abduction at 60

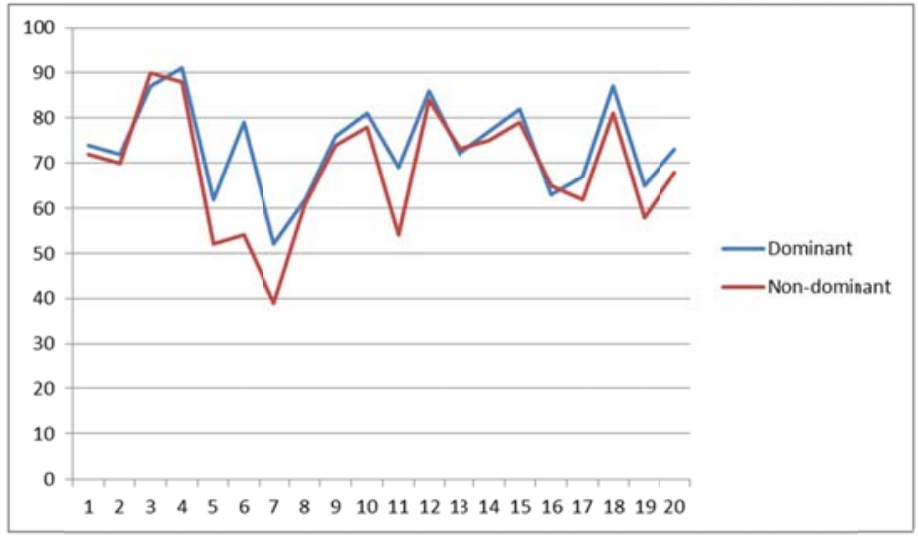
degrees per second 
Figure 6. Concentric adduction strength at 60 degrees per second

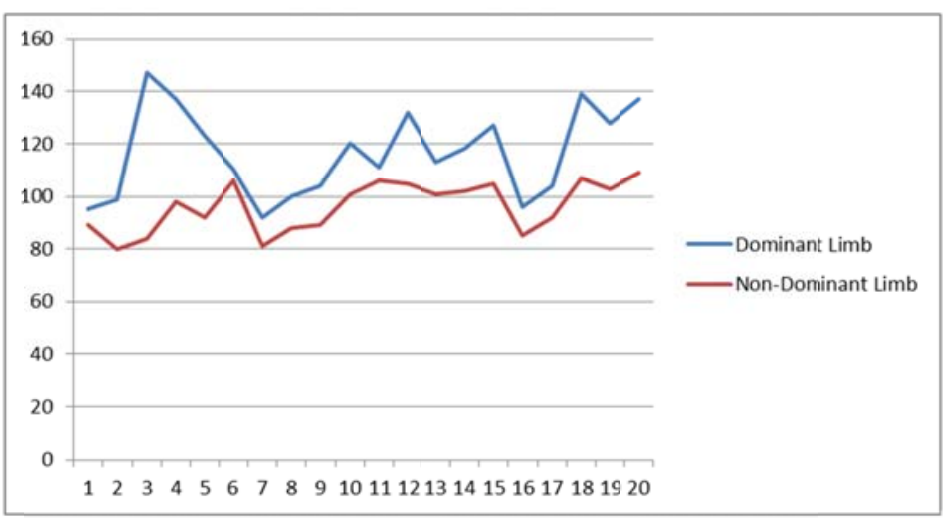

Table 2. Isokinetic results

\begin{tabular}{llllll}
\hline & Action & t values & $\boldsymbol{P}$ values & $\begin{array}{l}\text { Dominant limb ratio } \\
\text { (Mean } \pm \text { SD) }\end{array}$ & $\begin{array}{l}\text { Non-dominant limb ratio } \\
\text { (Mean } \pm \text { SD) }\end{array}$ \\
\hline Statistically & Con add:abd at 60 & 2.25 & .04 & $1.59 \pm 0.19$ & $1.45 \pm 0.31$ \\
significant & Ecc add:abd at 30 & 3.64 & .002 & $1.45 \pm 0.32$ & $1.26 \pm 0.26$ \\
difference & Con add:ecc abd at 30 & 2.66 & .016 & $1.26 \pm 0.34$ & $1.06 \pm 0.22$ \\
& Ecc add:con abd at 60 & 3.57 & .002 & $1.45 \pm 0.36$ & $1.21 \pm 0.22$ \\
& Con add:abd at 30 & 2.05 & .06 & $1.30 \pm 0.30$ & $1.17 \pm 0.28$ \\
No significant & Ecc add:abd at 60 & 1.32 & .07 & $1.46 \pm 0.26$ & $1.33 \pm 0.31$ \\
difference & Con add:ecc abd at 60 & 1.98 & .06 & $1.46 \pm 0.19$ & $1.34 \pm 0.29$ \\
& Ecc add:con abd at 30 & 1.71 & .10 & $1.53 \pm 0.42$ & $1.40 \pm 0.34$ \\
\hline
\end{tabular}

These results (see Figures 3-6; Table 2) allow the researcher to reject the null hypotheses as there was a significant difference between the concentric to concentric and eccentric to eccentric hip adductor to abductor strength ratios of elite academy football player's dominant and non-dominant limb at both speeds.

\section{Discussions}

Groin injuries are a major cause of lost playing and training time for professional football clubs. Rehabilitation and prevention of these injuries has been a major focus of many sports medicine clinicians over the last few years. Studies into other sports such as ice hockey have established normal values for hip adduction: abduction ratios. They have then used these values to compare players when screening them and identify those at risk of injury. Further to this they have then implemented programmes to normalise the player's strength ratios and demonstrated a reduced injury rate.

It is accepted that football player's hip strength requirements are very different to those of the predominantly closed chain ice hockey. The action with which football players kick a ball is open chain and most players use the same limb to do this every time (the dominant limb). This leads to unilateral strength differences and therefore the values applied to ice hockey for injury risk identification and prevention cannot be applied to football players.

Only one study ${ }^{[19]}$ has attempted to establish normal strength ratio's for elite football players. Unfortunately the measurement tool used was unreliable and unilateral differences were not identified ${ }^{[28,29]}$. There was no consensus on standard baseline hip adduction: abduction strength ratios for football players as a result of their study. Admittedly isokinetic dynamometers are costly and time consuming. In the clinical setting testing adductor strength with a pressure biofeedback unit might be a more convenient option and has been shown to be reliable in Rugby players ${ }^{[30]}$.

The initial aims of this study were to test uninjured elite academy football player's adduction and abduction strength ratios ratio's for both the dominant and non-dominant limbs, with the purpose of establishing normative data, which could be 
utilized to make recommendations for injury prevention. The measurements were taken using an isokinetic dynamometer which has been validated as a reliable measurement tool for hip adduction and abduction. These results showed that there was an asymmetry when specific speeds and contraction types were tested using isokinetic dynamometry. Overall the adductor: abductor strength ratios were lower on the non-kicking limb. However they were not below the 0.9 ratio which had previously been highlighted as a threshold for adductor strain risk in ice hockey players ${ }^{[16]}$. The results of this study suggests that the threshold may need to be raised to 1.3-1.6 for this cohort of football players; however further research is required to confirm that players with a ratio below this go on to develop an adductor strain. Further inspection of the results indicated that within the uninjured population the adductors have different strengths due to the different biomechanical loads placed upon them. This study provides some new data for the comparison of limb specific baseline adductor strength which may be useful to calculate return to sport decisions.

Another interesting finding of this study is that abductor strength was equal bilaterally. This finding, combined with increased adductor strength on the kicking limb, leads to a higher value for the adduction: abduction ratio on the kicking limb. This muscle imbalance supports one possible explanation for the high incidence of Femoral acetabular impingement (FAI) on the kicking limb in football players ${ }^{[5]}$. Therefore, it is suggested that in symptomatic players, abductor strength should be in order to lower the ratio and reduce the adductor dominance which has been proposed as a causative factor in FAI. Further research to determine if footballers who have high adductor: abductor strength ratios ultimately go on to develop FAI is needed. Should this be proven to be the case a threshold ratio for injury risk should be established. Players above this threshold can be then be identified via screening and their strength ratios can be normalized by increasing abductor strength to reduce injury rate.

\section{Limitations}

There were some limitations to this study one being the sample size could be viewed as unbalanced as it was a convenience sample of players available at a professional football club. Twenty participants were grouped on limb dominance. There were only 3 left limb dominant, and 17 right limb dominant participants included in the study however this could be representative of the populations dominance and comparison of results was dominant $v s$. non-dominant rather than left $v s$. right to minimize bias. This study was completed as part of the pre-season musculoskeletal screening examination therefore, limited to the convenience sample of players available, having a control group would have made this study more reliable but was unavailable in this environment.

Some consideration as to the validity of measurement since strength assessment might have been more appropriate tested dynamically. However as discussed in the methods section the reliability of isokinetic the dynamometer made it the testing tool of choice and it has ecological validity, as this is the process which is commonly utilized in professional football.

\section{Conclusions}

To summarize the content of this study, groin injuries are a major cause of lost playing and training time for professional football clubs. Rehabilitation and prevention of these injuries has been a major focus of many sports medicine clinicians over the last few years. Studies into other sports such as ice hockey have established normal values for hip adduction: abduction ratios. They have then used these values to compare players when screening them and identify those at risk of injury. Further to this they have then implemented programmes to normalise the player's strength ratios and demonstrated a reduced injury rate.

It is accepted that football player's hip strength requirements are very different to those of the predominantly closed chain ice hockey. Eccentric and concentric hip adduction and abduction strength of the dominant and non-dominant leg was tested on 20 English Premier League academy football players using a Cybex isokinetic dynamometer. 
The results of this study suggests that the threshold may need to be raised to 1.3-1.6 for this cohort of football players; however further research is required to confirm that players with a ratio below this go on to develop an adductor strain. Further inspection of the results indicated that within the uninjured population the adductors have different strengths due to the different biomechanical loads placed upon them. This study provides some important new data for the comparison of limb specific baseline adductor strength which may be useful to calculate return to sport decisions.

Another important finding of this study is that abductor strength is equal bilaterally. This finding, combined with increased adductor strength on the kicking limb, leads to a higher value for the adduction: abduction ratio on the kicking limb. Hip injuries in football are multifactorial. This muscle imbalance supports one possible explanation for the high incidence of FAI on the kicking limb in football players. Therefore, it is suggested that in symptomatic players, abductor strength should be increased in order to lower the ratio and reduce the adductor dominance which has been proposed as a causative factor in FAI. Further research to determine if footballers who have high adductor: abductor strength ratios ultimately go on to develop FAI is needed. Should this be proven to be the case a threshold ratio for injury risk should be established. Players above this threshold can then be identified via screening and their strength ratios can be normalized by increasing abductor strength to reduce injury rate.

\section{References}

[1] Arnason A, Sigurdsson SB, Gudmundsson A, et al. Risk factors for injuries in football. Am J Sports Med. 2004 ; 32 (1 Suppl): 5S-16S. PMid:14754854. http://dx.doi.org/10.1177/0363546503258912

[2] Nicholas SJ, Tyler TF. Adductor muscle strains in sport. Sports Med. 2002; 32(5): 339-44. http://dx.doi.org/10.2165/00007256-200232050-00005

[3] Hägglund M, Waldén M, Ekstrand J. Previous injury as a risk factor for injury in elite football: a prospective study over two consecutive seasons. Br J Sports Med. 2006; 40(9): 767-72. PMid:16855067. http://dx.doi.org/10.1136/bjsm.2006.026609

[4] Werner J, Hagglund M, Walden M, et al. UEFA injury study: a prospective study of hip and groin injuries in professional football over seven consecutive seasons. Br J Sports Med. 2009; 43: 1036-40. PMid:19945984. http://dx.doi.org/10.1136/bjsm.2009.066944

[5] Waldén M, Hägglund M, Ekstrand J. The epidemiology of groin injury in senior football: a systematic review of prospective studies. Br J Sports Med. 2015; 49: 792-7. PMid:25833901. http://dx.doi.org/10.1136/bjsports-2015-094705

[6] Nielsen AB, Yde J. Epidemiology and traumatology of injuries in soccer. Am J Sports Med. 1989; $17(6)$ : 803-7. http://dx.doi.org/10.1177/036354658901700614

[7] Muckle DS. Associated factors in recurrent groin and hamstring injuries. Br J Sports Med. 1982; 16(1): 37-9. PMid:7066614 . http://dx.doi.org/10.1136/bjsm.16.1.37

[8] Hölmich P. Long-standing groin pain in sportspeople falls into three primary patterns, a "clinical entity" approach: a prospective study of 207 patients. Br J Sports Med. 2007; 41(4): 247-52. PMid:17261557. http://dx.doi.org/10.1136/bjsm.2006.033373

[9] Ryan J, Deburca N, Mc Creesh K. Risk factors for groin/hip injuries in field-based sports: a systematic review. Br J Sports Med. 2014; 48: 1089-96. PMid:24795341. http://dx.doi.org/10.1136/bjsports-2013-092263

[10] Ekstrand J, Gillquist J. The avoidability of soccer injuries. Int J Sports Med. 1983; 4(2): 124-8. PMid:6874174. http://dx.doi.org/10.1055/s-2008-1026025

[11] Emery CA, Meeuwisse WH. Risk factors for groin injuries in hockey. Med Sci Sports Exerc. 2001; $33(9)$ : 1423-33. http://dx.doi.org/10.1097/00005768-200109000-00002

[12] Emery CA, Meeuwisse WH, Powell JW. Groin and abdominal strain injuries in the National Hockey League. Clin J Sport Med. 1999; 9(3): 151-6. PMid:10512343. http://dx.doi.org/10.1097/00042752-199907000-00006

[13] Knapik JJ, Bauman CL, Jones BH, et al. Preseason strength and flexibility imbalances associated with athletic injuries in female collegiate athletes. Am J Sports Med. 1991; 19(1): 76-81. PMid:2008935. http://dx.doi.org/10.1177/036354659101900113

[14] Orchard J, Marsden J, Lord S, et al. Preseason hamstring muscle weakness associated with hamstring muscle injury in Australian footballers. Am J Sports Med. 1997; 25(1): 81-5. PMid:9006698. http://dx.doi.org/10.1177/036354659702500116

[15] Tegner Y, Lorentzon R. Ice hockey injuries: incidence, nature and causes. Br J Sports Med. 1991; 25(2): 87-9. PMid:1751895. http://dx.doi.org/10.1136/bjsm.25.2.87

[16] Tyler TF, Nicholas SJ, Campbell RJ, et al. The association of hip strength and flexibility with the incidence of adductor muscle strains in professional ice hockey players. Am J Sports Med. 2001; 29(2): 124-8. PMid:11292035. 
[17] Tyler TF, Slattery AA. Rehabilitation of the hip following sports injury. Clin Sports Med. 2010; 29(1): 107-26. PMid:19945589. http://dx.doi.org/10.1016/j.csm.2009.09.005

[18] Tyler TF, Nicholas SJ, Campbell RJ, et al. The effectiveness of a preseason exercise program to prevent adductor muscle strains in professional ice hockey players. Am J Sports Med. 2002; 30(5): 680-3. PMid:12239001.

[19] Thorborg K, Couppé C, Petersen J, et al. Eccentric hip adduction and abduction strength in elite soccer players and matched controls: a cross-sectional study. Br J Sports Med. 2011; 45(1): 10-3. PMid:19850576. http://dx.doi.org/10.1136/bjsm.2009.061762

[20] Esteve E, Rathleff MS, Bagur- Calafat C, et al. Prevention of groin injuries in sports: a systematic review with meta-analysis of randomised controlled trials. Br J Sports Med. 2015; 49(12): 785-91. PMid:25730819. http://dx.doi.org/10.1136/bjsports-2014-094162

[21] Laheru D, Kerr JC, McGregor AH. Assessing hip abduction and adduction strength: can greater segmental fixation enhance the reproducibility? Arch Phys Med Rehabil. 2007; 88(9): 1147-53. PMid:17826460. http://dx.doi.org/10.1016/j.apmr.2007.05.017

[22] Charnock BL, Lewis CL, Garrett WE, et al. Adductor longus mechanics during the maximal effort soccer kick. Sports Biomech. 2009; 8(3): 223-34. PMid:19891200. http://dx.doi.org/10.1080/14763140903229500

[23] Li RC, Wu Y, Maffulli N, et al. Eccentric and concentric isokinetic knee flexion and extension: a reliability study using the Cybex 6000 dynamometer. Br J Sports Med. 1996; 30(2): 156-60. http://dx.doi.org/10.1136/bjsm.30.2.156

[24] Cahalan TD, Johnson ME, Liu S, et al. Quantitative measurements of hip strength in different age groups. Clin Orthop Relat Res. 1989; 24(6): 136-45. http://dx.doi.org/10.1097/00003086-198909000-00022

[25] Claiborne TL, Timmons MK, Pincivero DM. Test-retest reliability of cardinal plane isokinetic hip torque and EMG. J Electromyogr Kinesiol. 2009; 19(5): 345-52. PMid:18845450. http://dx.doi.org/10.1016/j.jelekin.2008.07.005

[26] Dugailly PM, Brassinne E, Pirotte E, et al. Isokinetic assessment of hip muscle concentric strength in normal subjects: A reproducibility study. Isokinetics and Exercise Science. 2005: 129-37.

[27] Myer GD, Brent JL, Ford KR, et al. A pilot study to determine the effect of trunk and hip focused neuromuscular training on hip and knee isokinetic strength. Br J Sports Med. 2008; 42(7): 614-9. PMid:18308886. http://dx.doi.org/10.1136/bjsm.2007.046086

[28] Pua YH, Wrigley TV, Wrigley TW, et al. Intrarater test-retest reliability of hip range of motion and hip muscle strength measurements in persons with hip osteoarthritis. Arch Phys Med Rehabil. 2008; 89(6): 1146-54. PMid:18503813. http://dx.doi.org/10.1016/j.apmr.2007.10.028

[29] Agre JC, Magness JL, Hull SZ, et al. Strength testing with a portable dynamometer: reliability for upper and lower extremities. Arch Phys Med Rehabil. 1987; 68(7): 454-8. PMid:3606371.

[30] Hodgson L, Hignett, Edwards K. Normative adductor squeeze tests scores in rugby. Physical Therapy in Sport. 2015; $16(2)$ : 93-7. PMid:25535035. http://dx.doi.org/10.1016/j.ptsp.2014.08.010 